\title{
PRAEDICATIO, PASSIO Y TRASLATIO: UN CICLO JACOBEO EN LAS PINTURAS MURALES DE LA IGLESIA DE SANTIAGO EL VIEJO DE SEVILLA
}

\author{
PRAEDICATIO, PASSIO AND TRASLATIO: A JACOBEAN \\ CYCLE AT THE MURAL PAINTINGS OF THE CHURCH \\ OF SAINT JAMES THE OLD IN SEVILLE
}

\author{
JAVIER Gómez DARriba \\ Universidad de Santiago de Compostela. España \\ ORCID: 0000-0001-6712-2983 \\ javier.gomez.darriba@usc.es
}

\begin{abstract}
La iglesia de Santiago el Viejo, en Sevilla, conserva tres pinturas murales con escenas de la vida y milagros del apóstol Santiago el Mayor. Se fechan entre las décadas de 1760 y 1770 y su autoría es desconocida. En el presente estudio analizamos su contenido y la posibilidad de que formasen parte de un ciclo pictórico jacobeo mucho mayor, constituyendo un ejemplo único en el mundo.

Palabras clave: Santiago el Mayor; pintura mural; siglo XVIII; iglesia de Santiago el Viejo; Sevilla.
\end{abstract}

The Church of Saint James the Old, in Seville, preserves three mural paintings with scenes from the life and miracles of the apostle Saint James the Greater. They are dated between the 1760s and 1770 s but the author is unknown. In the present study we analyze its content and the possibility that they were part of a much larger Jacobean pictorial cycle, it being a unique example in the world.

Keywords: Saint James the Greater; mural painting; $18^{\text {th }}$ century; Church of Saint James the Old; Seville.

${ }^{*}$ Este trabajo se enmarca dentro del proyecto del Ministerio de Economía, Industria y Competitividad Memoria, textos e imágenes. La recuperación del patrimonio perdido para la sociedad de Galicia HAR2014-53893-R, del que son investigadores principales Jesús A. Sánchez García y Alfredo Vigo Trasancos. También participa de la ayuda del Programa de consolidación de unidades de investigación competitivas do SUG, modalidad B: grupos con potencial de crecimiento (GPC), concedida por la Xunta de Galicia al grupo de investigación GI-1510 HAAYDU de la Universidad de Santiago de Compostela, del que es coordinador Alfredo Vigo Trasancos y que tiene como número de expediente ED413B 2016/003. 


\section{SEVILLA Y LA DEVOCIÓN A SANTIAGO EL MAYOR}

La ciudad de Sevilla, desde su conquista cristiana en 1248, se convirtió en un centro cultual jacobeo de primer orden, viviendo un punto álgido entre los siglos XVI y XVII. Por aquel entonces se hicieron en honor a Santiago tres retablos mayores y otras múltiples obras, entre las que destaca un gigantesco estandarte que en mayo de 1630 se colgó en la Giralda. Ninguna otra urbe peninsular, europea o americana asistió a una gestación artística equiparable. Pero Sevilla reunía motivos suficientes como para tributarle semejante devoción ${ }^{1}$. Para empezar, el origen cristiano de la ciudad se atribuía a la evangelización del apóstol en la Bética, mítica tradición que compartían otras muchas poblaciones. En nuestro caso se creía que Santiago había llevado a cabo la acción pastoral con su discípulo San Pío, a quien designó primer obispo de la diócesis, y a quien se atribuía la hechura de la imagen titular del primer templo cristiano de Híspalis, puesto bajo la advocación jacobea de la Virgen del Pilar, primera patrona de la ciudad ${ }^{2}$. Ahora bien, obviando este mito y respaldándonos en las fuentes documentales probadas, el origen del culto a Santiago en Sevilla no se retrotrae al siglo I, sino a la década de 1240, dentro del contexto reconquistador que procuraba el rey de Castilla y León Fernando III el Santo, cuyo ejército lo nutrían un buen número de caballeros de la orden de Santiago liderados por el maestre Pelay Pérez Correa, quien hasta la toma de Sevilla de 1248 había desempeñado un papel primordial en el sometimiento de distintas plazas de la actual provincia hispalense. Asimismo, la orden contribuyó a fijar los límites de la archidiócesis en el tercer cuarto del siglo XIII; y por si fuera poco, asumió la repoblación de vastos territorios conseguidos en época fernandina, en los que se asentó fundando parroquias, monasterios y encomiendas en las que ejerció jurisdicción. Tres de dichas encomiendas se hallaban cercanas a la capital, en pleno Aljarafe. A ellas habría que sumar la de Estepa y la de Santiago de la Espada, fundada esta última en Sevilla en 1409³.

${ }^{1}$ GÓMEZ DARRIBA, Javier: "Santiago Matamoros. Culto e iconografía en la Sevilla de 1535 a 1635", en Encrucijada de la palabra y la imagen simbólicas. Estudios de emblemática. Palma de Mallorca, 2017, pp. 365-386; y GÓMEZ DARRIBA, Javier: "Santiago Matamoros en Sevilla. Mito, arte y devoción”, Imago, 10, 2018, pp. 143-173.

${ }^{2}$ ESPINOSA DE LOS MONTEROS, Pablo: Primera parte, de la historia, antiguedades y grandezas, de la muy noble y muy leal Ciudad de Sevilla. Sevilla, 1627, f. 38r-38v; LINARES GARCÍA, Lidwine: "Los santos matamoros en la memoria de las ciudades: la celebración de un origen mítico", en Dire, taire, masquer les origines dans la péninsule Ibérique, du Moyen Âge au Siècle d'Or. Tolouse, 2013, pp. 63-64 y 72; y LINARES GARCÍA, Lidwine: "Le difficile héritage de la Reconquête espagnole: Saint Jacques Matamore, entre occultation et réappropriation", en Traces, Empreintes, Monuments, quels lieux pour quelles mémories? De 1989 à nos jours. Limoges, 2014, pp. 125-132.

${ }^{3}$ PEINADO SANTAELlA, Rafael Gerardo: "La Orden de Santiago en Sevilla", Cuadernos de Estudios Medievales, 4-5, 1976-1977, p. 181; RODRÍGUEZ BLANCO, 
La Reconquista se ligaba al papel que venía desempañando Santiago desde la Alta Edad Media como patrono de la monarquía hispana; como santo valedor de la misma ante cualquier conflicto armado; y como el más férreo defensor del catolicismo frente a los enemigos de la fe. De ahí su constante invocación contra los moros, que luego se extrapoló a moriscos, turcos otomanos, piratas berberiscos, reformados europeos, o naturales de las Indias. Santiago también conformaba un guardián de la navegación, una faceta que compartía con otros santos como San Telmo, San Nicolás de Bari o San Juan Nepomuceno, todos ellos de indiscutible devoción en una ciudad como Sevilla, cuya prosperidad dependió durante siglos del comercio marítimo-fluvial allí establecido ${ }^{4}$. Por otro lado, los arzobispos y el cabildo también fomentaron la devoción al apóstol. Le tributaron obras artísticas muy sobresalientes, y en el primer tercio del siglo XVII salieron en su defensa con un empeño denodado, oponiéndose rotundamente a que perdiese su exclusivo patronazgo sobre la Corona a costa de compartirlo con Santa Teresa ${ }^{5}$.

\section{LA IGLESIA DE SANTIAGO EL VIEJO Y LAS PINTURAS MURALES DEDICADAS A SANTIAGO}

Desde la citada conquista de tiempos de San Fernando, la ciudad contó con una iglesia parroquial dedicada a Santiago, popularmente conocida como de Santiago el Viejo. Este apelativo le viene porque fue el primero de los dos templos levantados en la urbe en honor al apóstol, pues el otro resultó el ya citado de Santiago de la Espada, hoy convento mercedario de la Asunción. Según la tradición, la referida iglesia parroquial se había construido sobre los terrenos en los que se hallaba la casa que había servido de morada al propio apóstol durante su estancia

Daniel: "El monasterio de Santiago de la Espada de Sevilla", Historia. Instituciones. Documentos, 6, 1979, p. 309; RODRÍGUEZ BLANCO, Daniel: "Las Órdenes Militares en el Reino de Sevilla en la Edad Media", Historia. Instituciones. Documentos, 39, 2012, pp. 288-292, 297-301, 308-316 y 322; RODRÍGUEZ BLANCO, Daniel: "Las Órdenes Militares en el Reino de Sevilla en la Edad Media. El contexto de la Encomienda Santiaguista de Estepa", en Cuadernos de Estepa. $N^{o}$ 01. Actas de las VII Jornadas sobre Historia de Estepa. De la Antigüedad Tardía a la Encomienda Santiaguista. La época medieval en el centro de Andalucía. Sesiones celebradas el 15, 16 y 17 de septiembre de 2008. Estepa, 2013, pp. 278-285, 289-293, 301-310 y 317; y LADERO QUESADA, Miguel Ángel: Historia de Sevilla. La ciudad medieval (1248-1492). Sevilla, 1989, pp. 16-18 y 197.

${ }^{4}$ DOMÍNGUEZ ORTIZ, Antonio: Historia de Sevilla. La Sevilla del siglo XVII. Sevilla, 1984; y MORALES PADRÓN, Francisco: Historia de Sevilla. La ciudad del Quinientos. Sevilla, 1989.

5 GÓMEZ DARRIBA, Javier: "Santiago Matamoros. Culto e iconografía...", op. cit., pp. 373-374 y 379-384; y GÓMEZ DARRIBA, Javier: "Santiago Matamoros en Sevilla...", op. cit., pp. 151-153 y 159-164. 
en Híspalis ${ }^{6}$. La fábrica del edificio actual se concluyó en 1556, aunque le sobrevinieron puntuales reformas en los siglos posteriores ${ }^{7}$. Sus paredes todavía albergan tres escenas pictóricas de la vida del santo patrono a las que la historiografía del arte no ha prestado suficiente atención. Dos de ellas se encuentran en los muros laterales del presbiterio, enfrentadas, mediando entre ambas el retablo mayor. Muestran la predicación y el martirio del apóstol respectivamente. Se enmarcan en sendos retablos pictóricos, flanqueándolas las columnas del primer cuerpo, sobre el que aparece un entablamento incurvado y un frontón partido, y, finalmente, un ático con un óculo coronado por un remate mixtilíneo ${ }^{8}$ (Figuras 1-3). El ornato guarda cierta consonancia con la decoración rococó incluida en el propio retablo en el último tercio del siglo $\mathrm{XVIII}^{9}$, sin que por ello se empleen aquí las rocallas ni otros motivos semejantes. Más bien, la tipología de los retablos pictóricos, los festones, las cintas, las guirnaldas o los angelotes retrotraen a modelos italianos del siglo XVII. La escena restante se halla en la nave de la epístola y exhibe un suceso relacionado con la traslación de los restos del apóstol a Galicia. El formato de su enmarque es idéntico al de sus homólogas del presbiterio, pero hoy día no se aprecian las arquitecturas fingidas que a buen seguro hubo de tener (Figura 4). Al menos se conserva la cartela con la ilegible leyenda alusiva al episodio, cuyos motivos ornamentales beben en última instancia del manierismo nórdico del último tercio del siglo XVI.

Sin lugar a dudas todas las escenas comparten autoría y época. Este hecho, sumado a la relativa arbitrariedad de su ubicación y a la disparidad de su propia temática dentro de la hagiografía jacobea, nos induce a pensar que en la segunda mitad del siglo XVIII se pintó un ciclo mucho más completo en buena parte de las paredes del templo, compuesto por un mayor número de episodios referentes a la vida y milagros del apósto ${ }^{10}$. Estilísticamente los temples pueden adscribirse

${ }^{6}$ GONZÁLEZ DE LEÓN, Félix: Noticia historica del origen de los nombres de las calles de esta M.N.M.L.Y.M.H. ciudad de Sevilla. Sevilla, 2008 (ed. facs., Sevilla, 1839), pp. 420-421; y GÓMEZ AZEVES, Antonio: Antigüedades, bellezas artísticas y sepulcros de la iglesia parroquial de Santiago, el Mayor, vulgo, el Viejo. Sevilla, 1865, p. 5.

7 GESTOSO Y PÉREZ, José: Sevilla monumental y artística. Historia y descripción de todos los edificios notables, religiosos y civiles, que existen en esta ciudad y noticia de las preciosidades artísticas y arqueológicas que en ellos se conservan. T. III. Sevilla, 1892, p. 461.

${ }^{8}$ Acerca de estos retablillos pictóricos véase HERRERA GARCÍA, Francisco Javier: "Retablos simulados. Aproximación al estudio del retablo pintado en Andalucía Occidental", en Atas do IV Congresso Internacional do Barroco Ibero-Americano. Ouro Preto, 2006, pp. 112-113.

${ }^{9}$ El retablo original se concluyó en 1600 y se debe a Vermondo Resta y a Andrés de Ocampo. PALOMERO PÁRAMO, Jesús Miguel: El retablo sevillano del Renacimiento: análisis y evolución (1560-1629). Sevilla, 1989, pp. 307-308.

${ }^{10}$ VALDIVIESO GONZÁLEZ, Enrique: Historia de la pintura sevillana. Siglos XIII al XIX. $3^{\text {a }}$ ed., Sevilla, 2002, p. 355; y VALDIVIESO GONZÁLEZ, Enrique: Pintura barroca sevillana. Sevilla, 2003, p. 590. 
a las décadas de 1760 y 1770 por las figuraciones y motivos arquitectónicos u ornamentales que presentan ${ }^{11}$. Pero desgraciadamente no hay constancia documental que nos ayude a precisar con mayor exactitud su datación, ni tampoco fuente alguna que nos revele la cantidad de escenas que conformarían el total de la serie. Incluso los eruditos y cronistas de los siglos XVIII y XIX, a la hora de tratar las obras artísticas de este templo, prefirieron centrarse en el lienzo del retablo mayor con la imagen ecuestre de Santiago, obviando así hacer referencias a las pinturas murales del apóstol ${ }^{12}$. Esta sorprendente omisión podría deberse a la posibilidad de que parte de este conjunto resultase dañado pocos años después de haberse pintado, pues en 1789 la iglesia se estaba "reedificando" tras haber "amenazado ruina", apuntalándose la nave mayor, mucho más alta que las colaterales ${ }^{13}$. Además, en julio de 1843 se deterioró de nuevo tras la caída de tres bombas y precisó de otra renovación ${ }^{14}$. Asimismo, tampoco habría que descartar la posibilidad de que aún hoy, ciertas escenas pictóricas pertenecientes a dicho ciclo permanezcan ocultas tras las capas de cal y/o los retablos.

Para colmo, no solo ignoramos con absoluta certeza la fecha de las pinturas o el número de episodios que las compondrían, sino que también desconocemos su autoría. Sin ningún rigor científico se han atribuido al pintor local Pedro Guillén, de quien prácticamente no se conoce obra alguna ${ }^{15}$. De este personaje poco

${ }^{11}$ Antonio de la Banda las consideró de hacia 1760. DE LA BANDA Y VARGAS, Antonio: "Ecos santiaguistas en Andalucía y Canarias", en Santiago. La Esperanza. Colegio de Fonseca, Universidade de Santiago, Santiago de Compostela, 17 de mayo-31 de octubre 1999. Santiago de Compostela, 1999, p. 113; y DE LA BANDA Y VARGAS, Antonio: "Ecos santiaguistas en Andalucía y Canarias", en Sentimientos de Camino. Santiago de Compostela, 2003, p. 242. Enrique Valdivieso, por su parte, de hacia 1770. VALDIVIESO GONZÁLEZ, Enrique: Historia de la pintura sevillana..., op. cit., p. 355.

12 Acerca del cuadro de Mateo Pérez de Alesio que ocupaba el retablo mayor y de su promotor Gonzalo Argote de Molina, véase la monografía de CABRILLANA CIÉZAR, Nicolás: Santiago matamoros, historia e imagen. Málaga, 1999. Así como los siguientes artículos: ALGARÍN GONZÁLEZ, Ignacio: "Nuevas visiones y aportaciones en la pintura «La Batalla de Clavijo», de la Iglesia de Santiago el Viejo de Sevilla", Laboratorio de Arte, 27, 2015, pp. 145-172; GÓMEZ DARRIBA, Javier: "Santiago Matamoros. Culto e iconografía...", op. cit., pp. 374-379; y GÓMEZ DARRIBA, Javier: "Santiago Matamoros en Sevilla...”, op. cit., pp. 154-159.

${ }^{13}$ ARANA DE VARFLORA, Fermín: Compendio historico descriptivo de la Muy Noble y Muy Leal Ciudad de Sevilla Metropoli de Andalucia. Sevilla, 2003 (ed. facs., Sevilla, 1789), p. 33

${ }^{14}$ GONZÁLEZ DE LEÓN, Félix: Noticia artistica historica y curiosa de todos los edificios publicos, sagrados y profanos de esta Muy Noble, Muy Leal, Muy Heroica e Invicta Ciudad de Sevilla, y de muchas casas particulares, con todo lo que les sirve de adorno artistico, antigüedades, inscripciones y curiosidades que contienen. T. II, Sevilla, 1844, pp. 215-216.

15 PERALES PIQUERES, Rosa María: La pintura sevillana de la segunda mitad del siglo XVIII. Tesis Doctoral, Universidad de Sevilla, 1987, p. 629; VALDIVIESO 
más se sabe que fue discípulo de Salvador de Illanes y que falleció en Sevilla en 1793 a decir de Ceán ${ }^{16}$. También que perteneció a la hermandad sacramental de la propia parroquia a mediados de siglo, dato que, a pesar de no tener una mayor relevancia, ha constituido el fundamento para atribuirle las pinturas murales de la capilla eucarística del templo, y por ende las de temática jacobea, habida cuenta de las evidentes similitudes formales entre ambas ${ }^{17}$. Sin ánimo de adscribírselas a ningún autor, sí cabe apuntar al menos que estilísticamente se asemejan a obras de Juan de Espinal y de Vicente Alanís ${ }^{18}$.

En lo que respecta al programa iconográfico, como se dijo, solo se conservan tres escenas que aluden a otros tantos momentos de la hagiografía jacobea. Entre sí resultan verdaderamente dispares y cada una representa un episodio de los ciclos de la praedicatio, passio y traslatio del apóstol. A su vez, la lectura de las mismas guarda un sentido cronológico-espacial, de tal forma que se desarrollan correlativamente desde el lado del evangelio hasta el de la epístola. La primera se halla en el flanco del evangelio del presbiterio y muestra a Santiago evangelizando al pueblo, un suceso poco frecuente dentro de la riquísima y variada iconografía jacobea $^{19}$ (Figura 1). Precisamente no muy lejos de Sevilla, el retablo mayor de la iglesia parroquial de Santiago en Carmona contiene un altorrelieve en que figura dicho episodio. Entre ambos existen claras semejanzas compositivas y formales, lo que quizá sea indicativo de que pudieron partir de un mismo modelo ${ }^{20}$ (Figura 5). Eso sí, la obra carmonense es anterior. Se sabe con certeza que el retablo fue

GONZÁLEZ, Enrique: Historia de la pintura sevillana..., op. cit., p. 355; VALDIVIESO GONZÁLEZ, Enrique: Pintura barroca sevillana, op. cit., p. 590; e ILLÁN MARTÍN, Magdalena; MALO LARA, Lina; SANTOS MÁRQUEZ, Antonio J. y VALDIVIESO GONZÁLEZ, Enrique: Pintura mural sevillana del siglo XVIII. Sevilla, 2016, p. 205.

${ }^{16}$ CÉAN BERMÚDEZ, Juan Agustín: Diccionario histórico de los más ilustres profesores de las bellas artes en España. T. II. Madrid, 1800, p. 242.

${ }_{17}$ Véase la nota al pie número 16.

${ }^{18}$ Sobre ambos pintores, consúltense las siguientes monografías: PERALES PIQUERES, Rosa María: Juan de Espinal. Sevilla, 1981; y CABEZAS GARCÍA, Álvaro: Vicente Alanís (1730-1807). Sevilla, 2011. Además, Francisco Javier Herrera ha apuntado la posibilidad de que el artífice de las pinturas de esta iglesia sea el de los retablos pictóricos de los muros laterales de la capilla del Nacimiento en la colegiata de Olivares (Sevilla). HERRERA GARCÍA, Francisco Javier: "Retablos simulados...”, op. cit., pp. 112-113.

${ }^{19}$ En este sentido, José María de Azcárate se mostró tajante al afirmar que "no hay duda de que el arte jacobeo nos ofrece el más rico y variado repertorio de asuntos de toda la hagiografía". DE AZCÁRATE RISTORI, José María: "La iconografía de Santiago en el Sacro Monte", Compostellanum, 10, 4, 1965, p. 879.

${ }^{20}$ Acerca de los grabados que sirvieron de base para la composición de diferentes imágenes de Santiago en la pintura sevillana de entre los siglos XVI y XVIII, véase GÓMEZ DARRIBA, Javier: "El apóstol Santiago y sus fuentes grabadas en la Sevilla de 1575 a 1750", en Coleccionismo, mecenazgo y mercado artístico en España e Iberoamérica. Sevi1la, 2017, pp. 715-731. 
ensamblado por Francisco de Ballesteros entre 1673 y 1681. La autoría de la traza se ha atribuido tanto a Bernardo Simón de Pineda como a Francisco Dionisio de Ribas. Y las esculturas le fueron adjudicadas contractualmente a Pedro Roldán, aunque por la calidad de las mismas se cree que se auxilió en su taller para llevarlas a cabo ${ }^{21}$. En ambas escenas Santiago se dispone sobre una roca desde la cual adoctrina a la muchedumbre de hombres, mujeres y niños concentrada ante él. $\mathrm{Su}$ auditorio comparte caracterizaciones faciales, gestos o atuendo, y lo mismo ocurre con el escenario, en cuyo fondo arquitectónico descuella un edificio cupulado. El apóstol viste túnica, manto, esclavina, y va descalzo, aunque en el relieve de Carmona se le añade la venera y el sombrero propios del peregrino. Bajo la escena del retablo pictórico sevillano se inscribe una cartela cuyo rótulo hace referencia al rol de Santiago como patrono de la monarquía española. La inscripción está tomada de una antífona del apóstol que incluso aparece en el breve emitido en 1681 por el papa Inocencio XI con motivo de la invalidación del patronato de San José en España ${ }^{22}$. Reza así: "O GLORIOSUM HISPANIAE REGNUM, TALI APOSTOLO, AC PATRONO MUNITUM!”. Esta clara alusión al rol del santo como patrono de España fue precisamente un hecho muy cuestionado durante los siglos XVII y XVIII ${ }^{23}$. La escenografía se completa con un óculo en el ático en el que dos angelotes revolotean sosteniendo lo que parece la esclavina o sombrero apostólico bajo la cruz santiaguista.

En resumidas cuentas, esta composición pone de manifiesto la labor evangelizadora de Santiago, acción que llevó a cabo por distintos lugares del mundo, cumpliendo así lo que Cristo le había encomendado (Mt 28, 16-20; Mc 16, 15-18). Las escuetas actas apócrifas relativas a este discípulo revelan que predicó por Judea y Samaria. Dichos textos se conocen como del Pseudo Abdías y se fechan hacia finales del siglo V e inicios del VI, aunque en última instancia se basan en la

${ }^{21}$ BERNALES BALLESTEROS, Jorge: Pedro Roldán. Maestro de Escultura (16241699). Sevilla, 1973, p. 69; HERRERA GARCÍA, Francisco Javier; QUILES GARCÍA, Fernando y SAUCEDO PRADAS, Consuelo: Carmona Barroca. Panorama artístico de los siglos XVII y XVIII. Sevilla, Carmona, 1997, p. 65; y RODA PEÑA, José: Pedro Roldán: escultor, 1624-1699. Madrid, 2012, pp. 245-246.

${ }^{22}$ LÓPEZ DE PRADO NISTAL, Covadonga: "Seguimiento de un grabado flamenco de Santiago Matamoros en impresos relacionados con causas compostelanas", en Actas del Congreso de Estudios Jacobeos. Santiago de Compostela, 1995, pp. 498-499.

${ }^{23}$ REY CASTELAO, Ofelia: La historiografía del Voto de Santiago. Recopilación crítica de una polémica histórica. Santiago, 1985; REY CASTELAO, Ofelia: Los mitos del apóstol Santiago. Santiago de Compostela, Vigo, 2006; REY CASTELAO, Ofelia: "La disputa del patronazgo de la Monarquía: Santiago o Santa Teresa", en La monarquía de Felipe III: la Casa del Rey. T. I. Madrid, 2007, pp. 227-246; y REY CASTELAO, Ofelia: "Teresa, patrona de España”, Hispania Sacra, 67, 136, 2015, pp. 531-573. 
obra de Clemente de Alejandría sobre la cual intervino Eusebio de Cesarea ${ }^{24}$. La primera fuente conservada que alude a la catequización de Hispania por parte de Santiago data de entre los siglos VI y VII. Se trata del Breviarium apostolorum ${ }^{25}$. En este aspecto reincide otro texto que durante siglos se atribuyó a Isidoro de Sevilla y que hoy se considera una interpolación del citado Breviario, el cual hubo de difundir por la península Ibérica la idea de que Santiago "predicó el evangelio a Hispania y al occidente; e infundió la luz de la predicación en el ocaso del universo" ${ }^{26}$. Esta creencia estuvo presente coetáneamente en tierras inglesas, pues un poema de 675 obra del abad Aldhelmo de Malmesbury incide en lo mismo. Por último, un himno litúrgico del último cuarto del siglo VIII dedicado a Santiago reitera su praedicatio ibérica y lo erige además como "cabeza de oro refulgente de Hispania" y "protector y patrono especial" de la monarquía asturiana ${ }^{27}$. En resumidas cuentas, se puede concluir que en el mayor de los hijos del Zebedeo se cumplió estrictamente lo expresado por su maestro: "seréis mis testigos en Jerusalén, en toda Judea, en Samaria y hasta los confines de la tierra" (Hch 1, 8). Y dentro de dichos confines, no debemos olvidar que la hagiografía moderna manifestó que Santiago "Predicô en la insigne ciudad de Seuilla, llamada entonçes Hispalis", dejando "en ella Obispo à su Discipulo Pio, que le auia acompañado

${ }^{24}$ DÍAZ Y DÍAZ, Manuel Cecilio: "La literatura jacobea anterior al Códice Calixtino", Compostellanum, 10, 4, 1965, pp. 640-642, y DEL CERRO CALDERÓN, Gonzalo y PIÑERO SÁENZ, Antonio (eds.): Hechos apócrifos de los apóstoles. T. III. Madrid, 2011, pp. 687-707.

${ }^{25}$ DÍAZ Y DÍAZ, Manuel Cecilio: "Literatura jacobea hasta el siglo XII", en Il pellegrinaggio a Santiago de Compostela e la letteratura jacopea. Atti del Convegno Internazionale di Studi. Perugia 23-24-25 Settembre 1983. Perugia, 1985, pp. 231-233.

${ }^{26}$ DE SEVILLA, Isidoro (aut.) y CHAPARRO GÓMEZ, César (trad.): De ortu et obitu Patrum. Vida y muerte de los santos. Introducción, edición crítica y traducción. París, 1985, pp. 25-29 y 202-204; y DÍAZ Y DÍAZ, Manuel Cecilio: "La literatura jacobea anterior al Códice Calixtino", op. cit., pp. 643-645.

${ }^{27}$ DÍAZ Y DÍAZ, Manuel Cecilio: "Literatura jacobea hasta el siglo XII", op. cit., pp. 235-236 y 238-239. La venida a Hispania del apóstol creó controversia a partir del siglo XVI, surgiendo alrededor de ella una puntillosa revisión crítica de documentos y leyendas, así como una bibliografía con detractores y defensores de la misma. Véase la nota a pie de página número 24 y consúltense entre otros a JODAR, Francisco de Jesús: Cinco discursos con que se confirma la Tradicion que el Apostol Santiago uino i predicò en España. Madrid, 1612; DE ERCE XIMÉNEZ, Miguel: Prueva evidente de la Predicacion del Apostol Santiago el Mayor en los reinos de España. Madrid, 1648; y DE MENDOZA Y SEGOVIA, Gaspar: Predicacion de Santiago en España, acreditada contra las dudas del Padre Christiano Lupo; y en desvanecimiento de los argumentos del Padre Nadal Alexandro. Zaragoza, 1682. 
desde Ierusalen". Con ello, la metropolitana Iglesia hispalense justificó durante siglos su fundación apostólica y que San Pío fuese su primer prelado ${ }^{28}$.

Precisamente Santiago sufrió el martirio como consecuencia de la predicación, escena que se plasma frente a la ya comentada. El apóstol, después de haber convertido a pocos hispanos en la Península, decidió regresar a los lugares en donde había iniciado su labor misionera, es decir, a Judea y Samaria. Allí sí logró grandes resultados, lo cual inquietó a las autoridades judaicas, que pronto estudiaron la forma de darle muerte ${ }^{29}$. La fuente primigenia que describe esta última etapa de su vida la supone el mentado texto apócrifo del Pseudo Abdías ${ }^{30}$, fidedignamente retomado tanto por el Liber Sancti Iacobi a mediados del siglo XII, como por la Leyenda Dorada en el XIII, siendo esta la principal difusora del mismo ${ }^{31}$. Según dicha narración, el pontífice Abiatar financió una sedición popular para capturar al apóstol. Acto seguido un escriba llamado Josías lo condujo hasta el pretorio del rey Herodes Agripa I, quien, tal y como describe el relato bíblico, "mandó ejecutar a Santiago, hermano de Juan" (Hch 12, 2), cumpliéndose así las palabras de Cristo: "Seréis llevados por mi causa ante gobernadores y reyes, para que deis testimonio ante ellos y ante los paganos" (Mt 10, 18). Conociendo el reinado durante el cual se produjo su decapitación, se concluye que tuvo lugar entre los años 41 y 44, y ello significa que Santiago fue el protomártir del colegio apostólico, hecho que desde un punto de vista histórico y hagiográfico siempre le fue valorado muy positivamente ${ }^{32}$. Precisamente la propia cartela pictórica

${ }^{28}$ CASTELLÁ FERRER, Mauro: Historia del Apostol de Iesus Christo Sanctiago Zebedeo Patron y Capitan General de las Españas. Madrid, 1610, ff. 75r y 85v.; CANO DE MONTORO, Hernando: Al Illustrissimo y Reverendissimo Señor Don Diego de Guzman, Patriarcha, Arçobispo de Sevilla. Sevilla, 1628, s. p.; y CALDERÓN, Antonio y PARDO VILLARROEL, Gerónimo: Excellencias y primacias del Apostol Santiago el Mayor, unico Patron de España, y Capitan General de las armas Catholicas. Madrid, 1658, p. 43.

${ }^{29}$ DE RIBADENEIRA, Pedro: Primera parte del Flos Sanctorum o Libro de las Vidas de los Santos en la qual se contienen las vidas de Christo N.S. y de su Santissima Madre; $y$ de todos los Santos de que reza la Yglesia Romana, por todo el año. Madrid, 1624, p. 473.

${ }^{30}$ A este manuscrito de entre los siglos V y VI se le acredita un origen en el sureste galo, concretamente en algún punto de influencia semita dado su carácter antijudaico. DÍAZ Y DÍAZ, Manuel Cecilio: "La literatura jacobea anterior al Códice Calixtino", op. cit., pp. 640-642. Dicha fuente no ha de confundirse con los evangelios apócrifos, como ocurre en MARCHENA HIDALGO, Rosario: Las miniaturas de los libros de coro de la catedral de Sevilla: el siglo XVI. Sevilla, 1998, pp. 244 y 246.

${ }^{31}$ Liber Sancti Iacobi, lib. I, cap. IX. FEO GARCÍA, Julio; MORALEJO LASO, Abelardo y TORRES RODRÍGUEZ, Casimiro (trads.): Liber Sancti Iacobi, Codex Calixtinus. Santiago de Compostela, 2004 (ed. orig., 1951), pp. 113-123; y DE LA VORÁGINE, Santiago (aut.) y MACÍAS, José Manuel (trad.): La leyenda dorada. T. I. $2^{\text {a }}$ ed., Madrid, 1987 (ed. orig. de 1982), pp. 397-399.

${ }^{32}$ Aun así Santiago no fue el primer santo fallecido por la causa de Cristo, tal consideración la ostenta San Esteban (Hch 7, 54-60). 
que figura bajo la escena de su muerte en el mural sevillano recalca esta virtud: "O BEATUM APOSTOLUM, QUI PRIMUN OMNIUM APOSTOLORUM DNI [DOMINI], CALICEM BIBERE MERUIT!’. Además, dicha oración, tomada una vez más de una antífona, parece aludir de alguna manera a la promesa que Santiago y su hermano Juan habían hecho a Cristo respecto a que serían los primeros en sacrificarse o beber de la copa de amargura a imagen y semejanza de su maestro (Mt 20, 20-23; Mc 10, 35-40). La escena dieciochesca, que por cierto ofrece un alarmante estado de conservación, destaca por su dramatismo (Figura 2). El cuerpo del apóstol yace decapitado y maniatado sobre un banco, y su verdugo, en presencia de varios soldados ataviados con armadura moderna, ofrece la testa a dos personajes que seguramente se correspondan con Herodes Agripa I y Abiatar. En la parte superior aparece un coro angélico sustentando la corona y la palma martiriales, mientras que en el ático del retablo pictórico figuran dos ángeles: uno sostiene el bordón y el otro bebe de la calabaza, dos atributos jacobeos característicos de su iconografía como peregrino. Sobre ellos, una vez más, la cruz de la orden de Santiago (Figura 3).

Respecto a la última escena, conviene apuntar primeramente que el cuerpo del apóstol fue descubierto en la primera mitad del siglo IX en un terreno sobre el que hoy se levanta la catedral de Santiago de Compostela. Por aquel entonces se asumía que había muerto a miles de kilómetros y que había predicado en Hispania, con lo cual, la invención de sus restos en la península Ibérica validaba aquel dicho de San Jerónimo de que cada apóstol descansaba allí donde había llevado a cabo su labor misionera ${ }^{33}$. Ahora ya solo faltaba por acreditar la manera en que su cadáver había sido conducido desde Jerusalén hasta el ocaso del Occidente conocido ${ }^{34}$. La solución a dicha cuestión la dio la Pseudoepístola del Papa León, redactada a mediados del siglo IX y de posible origen gallego. Se sabe de ella gracias a dos textos posteriores, siendo uno de ellos el citado Liber Sancti Iacobi ${ }^{35}$. La Leyenda Dorada y

${ }_{33}$ DÍAZ Y DÍAZ, Manuel Cecilio: "Literatura jacobea hasta el siglo XII”, op. cit., p. 226.

${ }^{34}$ Sobre el estudio crítico de las fuentes acerca de la traslatio del apóstol consúltese LLINARES GARCÍA, Mar: "La reina Lupa entre la leyenda literaria y la tradición popular", Cuadernos de Estudios Gallegos, 38, 103, 1989, pp. 299-320; DÍAZ Y DÍAZ, Manuel Cecilio: "La Epístola Leonis Pape De Translatione Sancti Iacobi in Gallaeciam", Compostellanum, 43, 1998, pp. 517-568; CEBRIÁN FRANCO, Juan José: “Los «Relatos de la Traslación del Apóstol Santiago» a Compostela", Compostellanum, 52, 3-4, 2007, pp. 370470; y BERMEJO BARRERA, José Carlos y LLINARES GARCÍA, Mar: "El rey de Hispania, la señora Lupa y el sepulcro del apóstol Jacobo. Estructura y génesis de una leyenda hagiográfica”, Boletín Auriense, 47, 2017, pp. 9-48.

${ }_{35}$ DÍAZ Y DÍAZ, Manuel Cecilio: "La literatura jacobea anterior al Códice Calixtino", op. cit., pp. 652-ss.; DÍAZ Y DÍAZ, Manuel Cecilio: "Literatura jacobea hasta el siglo XII", op. cit., pp. 243-244; y LÓPEZ ALSINA, Fernando: La ciudad de Santiago de Compostela en la Alta Edad Media. Santiago de Compostela, 1988, pp. 121-125. De todos modos, una reciente investigación sugiere que el relato de la traslatio podría tener sus orígenes en el 
otras hagiografías modernas añadieron más ingredientes anecdóticos a esta traslatio, en la que los varones apostólicos y los venerables restos que custodiaban sufrieron todo tipo de acontecimientos en territorio galaico. Comenta la Pseudoepístola que luego de degollar al apóstol, los judíos impidieron que los cristianos jerosolimitanos le diesen sepultura, dejando su cadáver a merced de las alimañas. Santiago había encomendado a sus discípulos que lo trasladasen a Hispania una vez muriese, y ellos cumplieron con lo apalabrado y se embarcaron por el Mediterráneo. En apenas siete días cruzaron los mares y alcanzaron Iria Flavia, y todo gracias a que su nave fue guiada por la Divina Providencia. Tras arribar, portaron el cuerpo hasta una propiedad de la pagana reina Lupa, con quien tuvieron una audiencia en la cual solicitaron entierro para su maestro ${ }^{36}$. La soberana les indicó con perversas intenciones que acudieran junto al rey de Duio, pues él sabría qué hacer con los restos. Los varones apostólicos se dirigieron hasta su palacio, próximo a Finisterre, y según el Liber Sancti Iacobi, mientras duraba la embajada, el monarca comenzó a urdir una emboscada. La gracia divina hizo que los discípulos fuesen conscientes de ello y huyeron del lugar, cosa que no permitió el rey tan fácilmente, pues ordenó a sus caballeros que los capturasen; de hecho los acompañó en tal cometido, y cuando solo les quedaba cruzar un puente para apresarlos, este se derruyó al paso del séquito, no sobreviviendo ni tan siquiera el soberano. Dicho texto remarca conscientemente la analogía entre este suceso y el veterotestamentario del faraón y su ejército absorbidos por las aguas del mar Rojo en su persecución al Pueblo de Israel $^{37}$. La Leyenda Dorada modificó parcialmente este episodio y las hagiografías posteriores prefirieron la versión de Santiago de la Vorágine, quien tuvo la deferencia de citar las fuentes en las que se había basado para compendiarla. Así, señaló que Juan Beleth había tomado al personaje recomendado por Lupa como un simple hombre cruel, en tanto que otros autores lo habían identificado como el rey de Hispania. Este, luego de atender la petición de los varones de inhumar a Santiago, mandó a sus soldados que los encarcelasen. Caída la noche un ángel los liberó, y enterado el rey al amanecer, ordenó a su hueste que los persiguiese, pero sucumbió en el intento de cruzar el puente. Informado de lo sucedido, envió a unos emisarios para que los discípulos regresasen a palacio, donde les comunicó que a partir de

mundo anglosajón de los siglos VI y VII. BERMEJO BARRERA, José Carlos y LLINARES GARCÍA, Mar: "El rey de Hispania, la señora Lupa...", op. cit., pp. 32-34.

${ }^{36}$ Historia Compostelana, lib. I, cap. I. CAMPELO, José y SUÁREZ, Manuel (trad.): Historia Compostelana o sea Hechos de D. Diego Gelmírez. Primer Arzobispo de Santiago. Santiago de Compostela, 1950, pp. 19-20; y Liber Sancti Iacobi, lib. III, cap. I, op. cit., pp. 390-391. Acerca de los varones apostólicos consúltese CASTRO PÉREZ, Ladislao; DE PRADA CREO, Elena y REBOREDA MORILLO, Susana: "Luparia y el culto de los santos Eufrasio y Torcuato", en Actas del Congreso de Estudios Jacobeos. Santiago de Compostela, 1995, pp. 129-134.

37 Liber Sancti Iacobi, lib. III, cap. I, op. cit., pp. 392-393. 
entonces podrían evangelizar sus tierras ${ }^{38}$. Juan B. Santoro estimó a dicho rey como un príncipe y añadió que él también se convertía ${ }^{39}$. Castellá Ferrer agregó que a este se le tenía tradicionalmente por hermano de Lupa. Además dio nombre al puente, conocido como de Ous, porque con tal vocablo se expresaba espanto en lengua gallega ${ }^{40}$. Ojea, por su parte, adujo que el instigador de la persecución se arrepintió y se bautizó. Este autor no lo consideró rey, si acaso un pretor o presidente de la chancillería residente en Lugo, gobernador al fin y al cabo de la comarca de Iria ${ }^{41}$.

En la nave colateral de la epístola figura en un pésimo estado de conservación la pintura que representa a la tropa del rey de Duio precipitándose a las aguas del Tambre luego de que se destruya el puente por voluntad divina (Figura 4). Algunos de los varones apostólicos ya se encuentran a salvo en la orilla, atónitos por el suceso, mientras que los portadores del cuerpo de Santiago, rezagados, todavía no han terminado de atravesarlo. Al otro lado del río se aprecia la ciudadela regia, toda ella amurallada, con arquitecturas cupuladas en su interior y dominada por una alta torre cuadrangular. El instante aquí pintado ha de valorarse y mucho por la sencilla razón de que supone una rara avis dentro de la iconografía jacobea. De hecho ni tan siquiera la catedral compostelana, rica en temática santiaguista como ningún otro templo, cuenta con ejemplos tan señeros del mismo, pues los pocos que hay son muchísimo menos visibles tanto por su exiguo tamaño como por su localización ${ }^{42}$. Así, los hallamos en los relieves de la peana añadida entre 1571 y 1577 a la custodia de asiento de Antonio de Arfe, quizá siguiendo dibujos del polifacético artista aragonés Juan Bautista Celma, quien reitera el tema en el púlpito del lado del evangelio llevado a cabo entre 1578 y $1586^{43}$. O en las pinturas de la bóveda de la antesala capitular, debidas a Manuel Arias Varela en la década de $1780^{44}$. Ninguna de estas representaciones guarda concomitancias compositivas con la hispalense.

${ }^{38}$ DE LA VORÁGINE, Santiago (aut.) y MACÍAS, José Manuel (trad.): La leyenda dorada..., op. cit., pp. 399-400.

${ }^{39}$ SANCTORO, Juan Basilio: Segundo Volumen de la Hagiographia, y vidas de los sanctos del nuevo Testamento. Bilbao, 1580, f. 45r.

${ }^{40}$ CASTELLÁ FERRER, Mauro: Historia del Apostol..., op. cit., ff. 129v-130v.

${ }^{41}$ OXEA, Hernando: Historia del Glorioso Apostol Santiago Patron de España: de su venida a ella, y de las grandezas de su Yglesia, y Orden militar. Madrid, 1615 (ed. orig. de $1612)$, ff. $56 \mathrm{r}-57 \mathrm{v}$.

${ }^{42}$ Dentro de lo mucho publicado sobre la iconografía jacobea en la catedral de Santiago, por su carácter compilador y reciente, conviene acudir a la monografía de GARCÍA IGLESIAS, José Manuel: Santiagos de Santiago. Dos apóstoles al final del Camino. Santiago de Compostela, 2011.

${ }^{43}$ GARCÍA IGLESIAS, José Manuel: "Antonio de Arfe y Juan Bautista Celma. Dos modos de interpretar, desde el arte, el paisaje", Quintana, 11, 2012, pp. 61-62, 67-68 y 74-75.

${ }^{44}$ FERNÁNDEZ CASTIÑEIRAS, Enrique: "Aproximación a la historia de la pintura gallega de la segunda mitad del siglo XVIII”, Adaxe, 9, 1993, p. 38; y FERNÁNDEZ 
Dicho esto, sería conveniente teorizar sobre qué otras escenas pudieron formar parte de esta serie jacobea, siempre y cuando no se conserven tras las capas de cal o los retablos. Dada la correlación cronológico-espacial que evidencian las existentes, probablemente la nave colateral del evangelio luciese las relativas al ciclo evangélico del apóstol. Y así, no sería de extrañar que una mostrase a Cristo eligiendo a Santiago y a Juan como sus discípulos, dejando estos los aparejos de pesca para seguir a su maestro (Mt 4, 18-22; Mc 1, 16-20). También parece probable que tuviese cabida el episodio en que ambos hermanos -por sí mismos o gracias a la intercesión de su madre María Salomé-, ruegan a Cristo los mejores puestos en su reino, suceso que constituye la prefiguración del martirio de todos ellos (Mt 20, 17-23; Mc 10, 32-40). Tampoco habría que descartar que luciese alguno de los episodios en que los hermanos y el apóstol Pedro son los únicos testigos de acontecimientos verdaderamente importantes en la vida de Cristo, entre los que destacan la Transfiguración y la Oración en el Huerto. Del mismo modo, la aparición de la Virgen sobre el pilar en Zaragoza también podría formar parte de las pinturas de dicha nave. Habida cuenta de la temática de los murales del presbiterio y de la referida correlación cronológica de las escenas, cabría descartar que hubiese alguna relativa a los milagros que el apóstol hizo ante los magos Fileto y Hermógenes, que, a la postre, supusieron la conversión de estos al cristianismo poco antes de que Herodes Agripa I le diese muerte a Santiago. En la nave de la epístola parece lógico que una escena relativa al viaje marítimo de su cadáver hasta Galicia antecediese a la que se conserva del puente, y que a esta última le siguiesen otras de carácter milagroso, bien relativas a la reina Lupa; al hallazgo de su cuerpo en Compostela; a la ayuda prestada a peregrinos, marineros y demás personajes; o, sencillamente, que apareciese una efigie de Santiago caracterizado como peregrino. Desde luego todo apunta a que un ciclo semejante a este hubo de lucir en los muros del templo parroquial durante la segunda mitad del siglo XVIII, lo que lo convertiría en un ejemplo único en el mundo pese a que Santiago cuenta a lo largo y ancho del orbe cristiano con centenares de iglesias dedicadas.

Fecha de recepción: 30 de octubre de 2018

Fecha de aceptación: 1 de julio de 2019

CASTIÑEIRAS, Enrique y MONTERROSO MONTERO, Juan Manuel: A pintura mural nas catedrais galegas. Santiago de Compostela, 2006, pp. 128-129 y 136. 


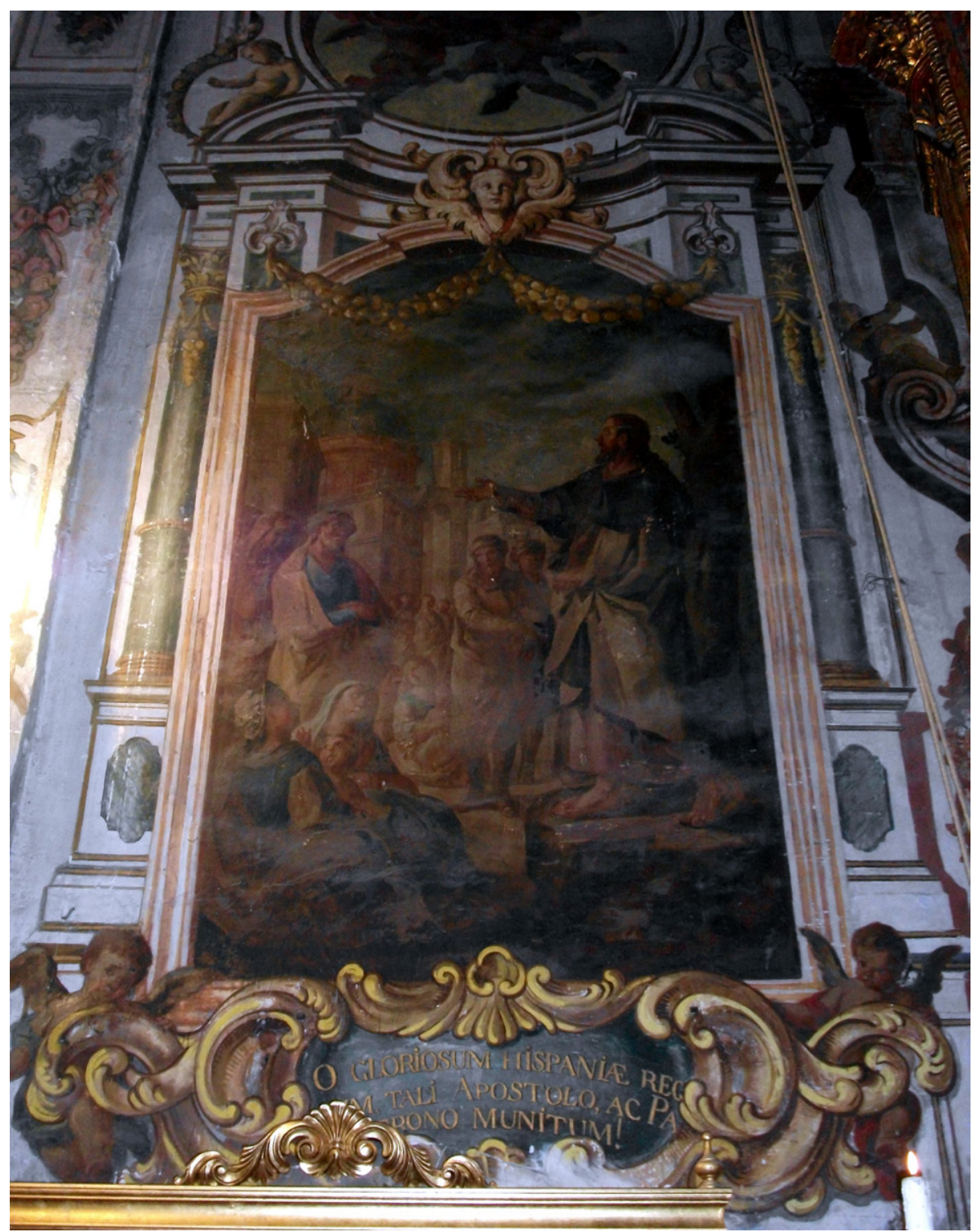

Figura 1. Predicación de Santiago, décadas de 1760-1770, iglesia de Santiago, Sevilla. Foto: Javier Gómez Darriba. 


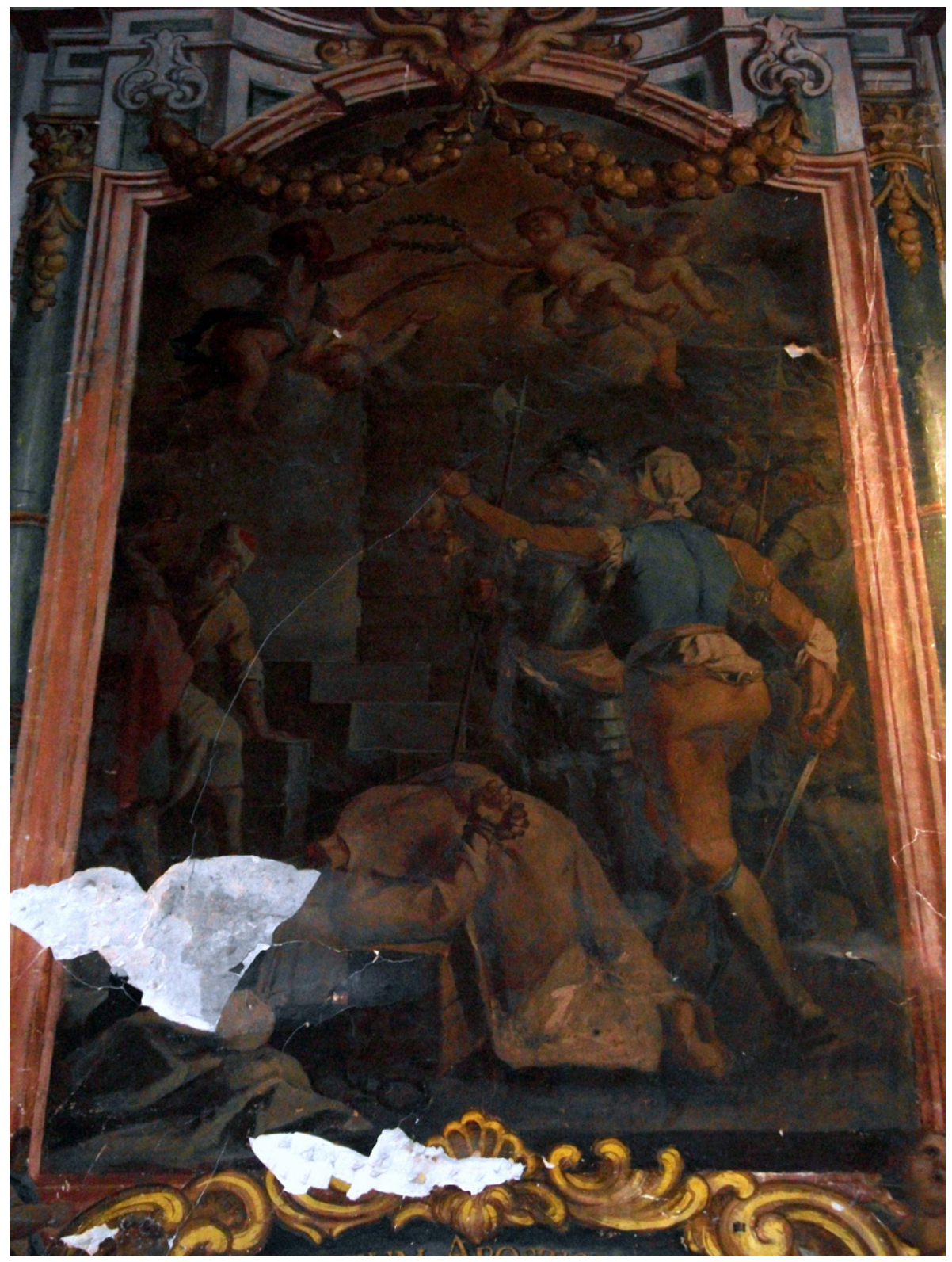

Figura 2. Martirio de Santiago, décadas de 1760-1770, iglesia de Santiago, Sevilla. Foto: Javier Gómez Darriba. 


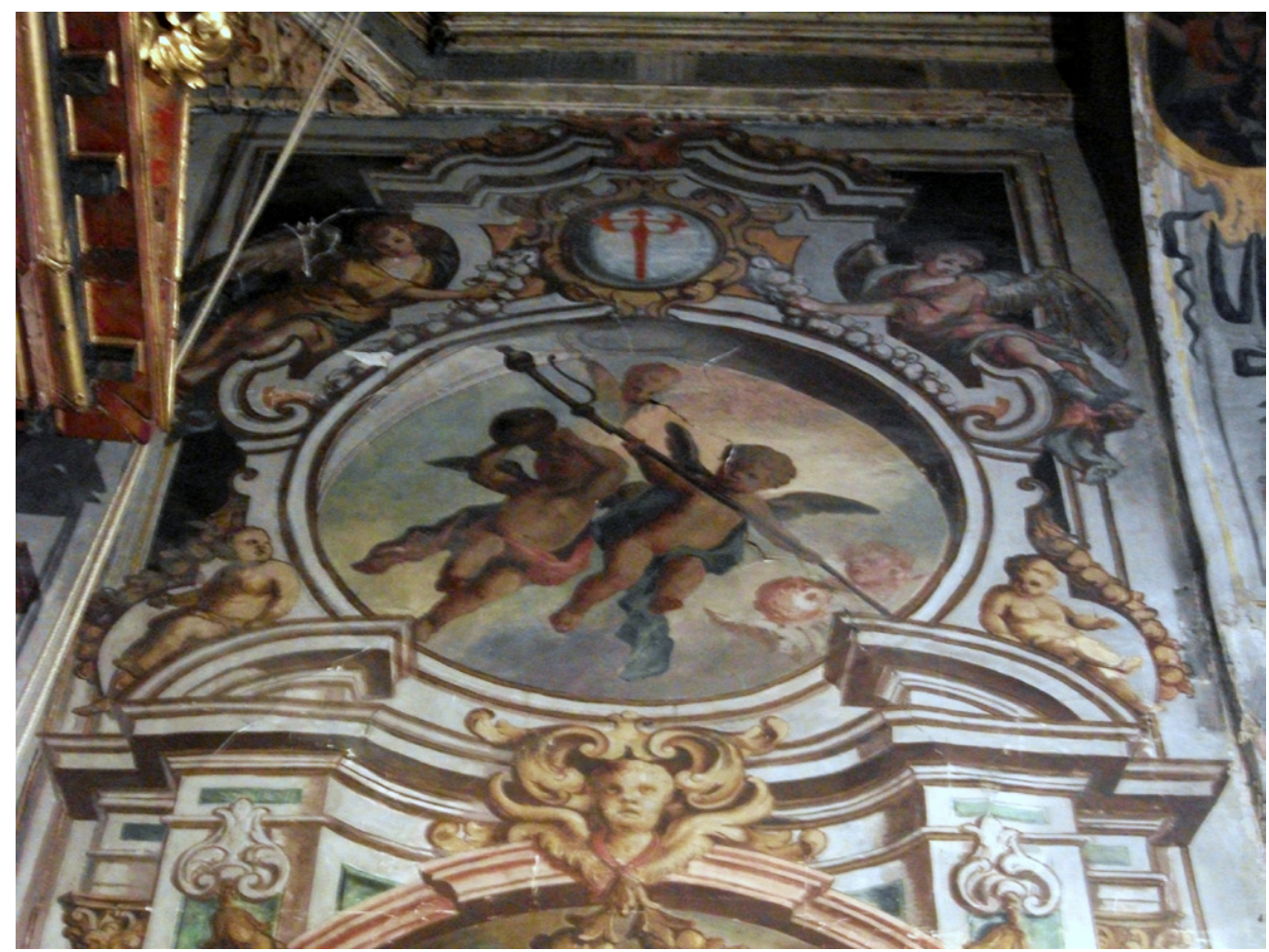

Figura 3. Dos angelotes sostienen atributos jacobeos en el ático del retablo pictórico del presbiterio, décadas de 1760-1770, iglesia de Santiago, Sevilla. Foto: Javier Gómez Darriba. 


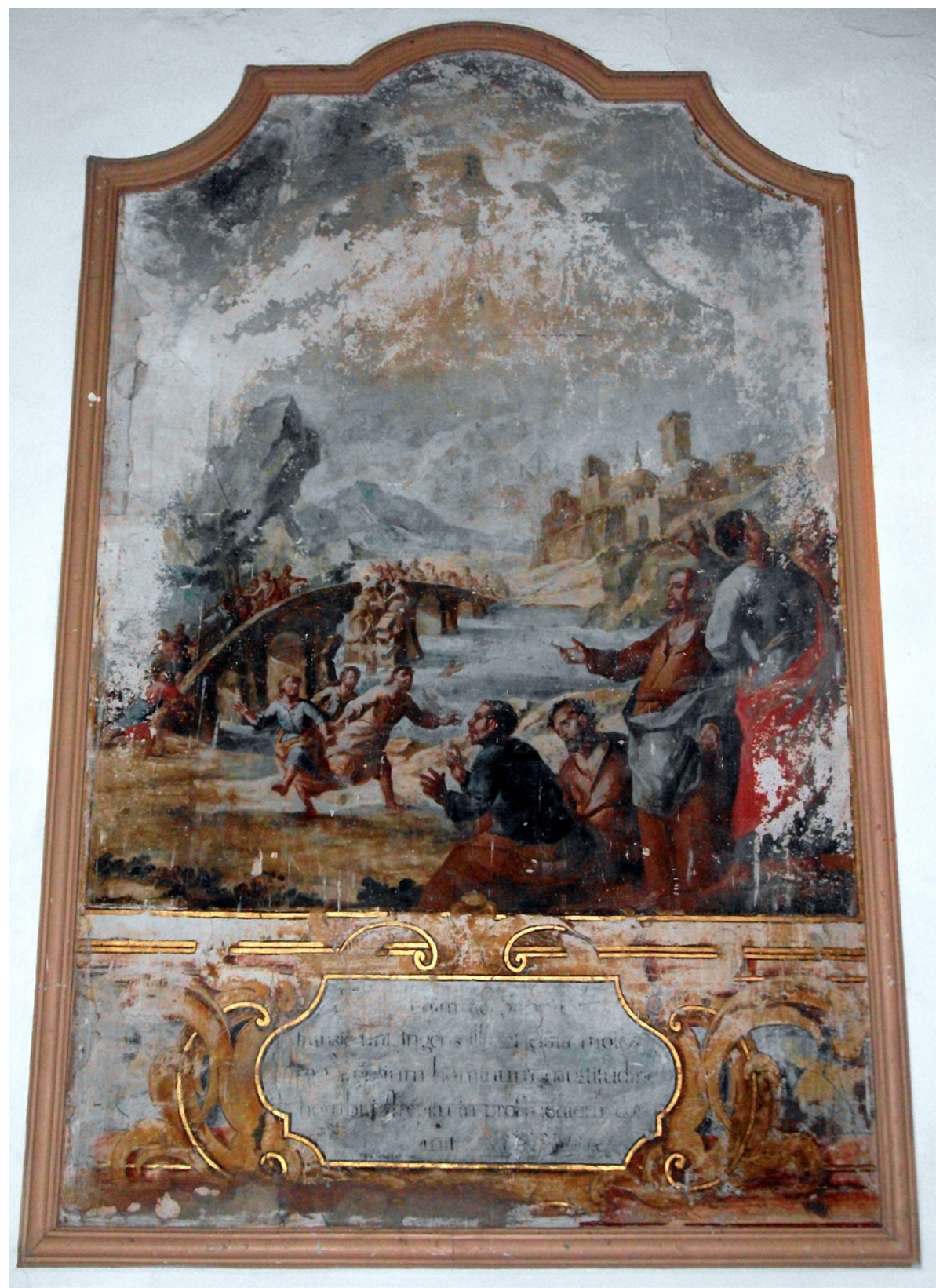

Figura 4. Milagro del puente, décadas de 1760-1770, iglesia de Santiago, Sevilla. Foto: Javier Gómez Darriba. 


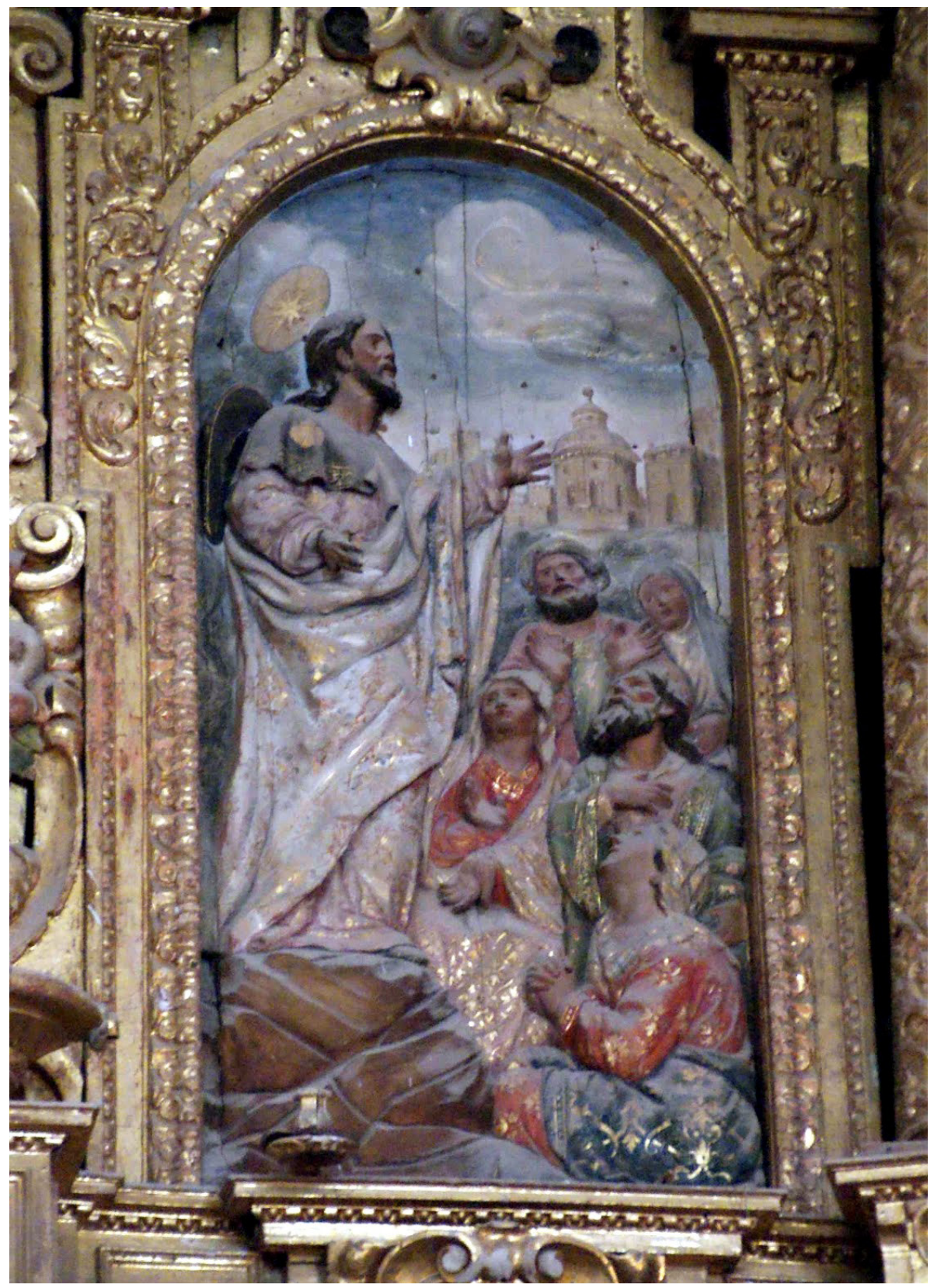

Figura 5. Predicación de Santiago, último cuarto del siglo XVII, iglesia parroquial de Santiago, Carmona. Foto: leyendasdesevilla.blogspot.com. 